\title{
Foresight for development of innovation ecosystems in Russian education: information basis of evaluation
}

\author{
Daniel $V$. Petrosyants ${ }^{1 *}$, Konstantin $V$. Simonov ${ }^{1}$, Stanislav P. Mitrakhovich ${ }^{1}$, and Igor $V$. \\ Iushkov $^{1}$ \\ ${ }^{1}$ Financial University under the Government of the Russian Federation, Department of Political \\ Science, Moscow, Russia
}

\begin{abstract}
This article attempts to forecast the pattern of development and bottlenecks during rearrangement of the Russian system of higher education in short- and medium-terms. The authors apply system analysis to study the existing realities of various aspects characterizing successfulness and opportunities to achieve academic leadership by leading Russian universities. This work maps out the existing visually perceived state of innovation ecosystems in some leading Russian universities. The studies cover such aspects of development of modern universities as budgeting and properties of its constituents, ability of universities to efficiently perform research and to use the obtained results, transition to mastering and development of various EdTech methods, policy of educational entities in the field of further education and further vocational education. This work describes the approach offering the use of university rating for foresight evaluation of development of Russian universities. The authors believe that in the nearest future the students will be more independent regarding selection of the required knowledge at universities, aiming at acquiring individually-oriented knowledge; the complex system of interaction between universities and ambient world demonstrates not only the importance of high-quality educational process but also of professionally arranged information communication channels.
\end{abstract}

Keywords: academic leadership, higher education, expert evaluations, scientometrics.

\section{Introduction}

In modern rapidly changing world, it is required to reorient the vectors of society efforts applied to formation and development of higher education system. The established and existing for several centuries classical universities, the so called ivory towers, had no competition from other institutions offering educational services. They possessed the monopoly for knowledge transfer, usually they had powerful libraries. The universities passed through numerous metamorphoses being classified according to various models, for instance, pre-classic, classic, and post-classic. Shchedrovitsky highlights five generations of

\footnotetext{
*Corresponding author: dan-basa@yandex.ru
} 
universities, this is supported by numerous examples [1]. The essence is that at present, the competition to universities is generated by the institutions, which did not play on this ground: institutions ranging from corporations (in Russia these are mainly development institutions) to online aggregators. We mean digital educational technologies (EdTech), they are the ones that open new opportunities for all kinds of education, including further education and further vocational education for adults [2,3].

Human capital is one of the most important factors of modern economy, promoting sustainable development; thus, the interest to investment into education as a driving force of human capital of the future inevitably increases [4]. The efficient role of investments into education upon achievement of comprehensive economic and social development is already widely recognized [5].

Is there an opportunity to reliably forecast future development of education system in the world and in Russia? Of course, reliability of the evaluation will depend on numerous unpredictable factors. At present, the models of extrapolation of existing time series to further events provide very low success rate of predictions. Basically, any model does not take into account all nuances of reality, though, some features and trends of development can be assumed with certain confidence at present.

\section{Methods}

The research methodology was based on general and special methods of scientific cognition: empirical studies (monitoring, comparison, acquisition, and analysis of data), current and prospective analysis and synthesis of theoretical and practical material, multifactorial system analysis, sociology, statistical analysis, etc.

The authors used the data from the following web sites:

- official website of the Ministry of Science and Higher Education of the Russian Federation. National project: Education (https://edu.gov.ru/national-project);

- official website of the Federal State Statistics Service of the Russian Federation (http://www.gks.ru);

- Scopus abstract database (http://www.scopus.com);

- Russian Science Citation Index (RSCI) (http://www.elibrary.ru.);

- SCAN-Interfax. Monitoring and analysis of Russian mass media environment (http://scan-interfax.ru).

\section{Results}

The research results are comprised of a series of conclusions and evaluations, confirmed by authors' computations and analysis:

1. The development prospects of the modern Russian system of higher education have been evaluated;

2. Budgeting of leading Russian universities has been analyzed in terms of attracting extrabudgetary sources and share of revenue from research in university budget;

3. Foresight evaluation is proposed for further route of development of Russian universities: participants in the Strategic Academic Leadership Program (SALP).

\section{Discussion}

In recent time there are numerous discussions concerning pertinence and demand for university ratings. Many people have already learned to subdivide and to evaluate the differences of methods; and informatively valuable for various stakeholders are subject 
ratings, the demand for which is becoming more and more intensive in our country in recent years. The issue is how to arrange a model of rating evaluation, which parameters will be demanded in five, ten, twenty years. Will the ivory towers be able to stay in business? Many alternative institutions offering educational services are already outperforming traditional universities in terms of some parameters. There are some questions about the ability of universities to be active participants in development of regional economies [6], including the national projects [7]. Will SALP be able to reboot numerous programs of education development in Russia aimed at competitiveness improvement? Is there a contradiction in competitiveness development of Russian universities, if the most successful graduates obtaining competitive at world level education are not always demanded by Russian economy and are not employed in regions? $[8,9]$

Let us try to approach the future and assume trends of the nearest and remote future based on the analysis of the present reality. It is obvious that the interest will be attracted to the efficiency of education transferred in a wide sense from generation to generation. Equally important is the innovative local or global ecosystem, which is created in numerous fields by university itself. The EU experience, which can be relevant for the Russian Federation, demonstrates that material limitations can be inherently secondary, the universities nearly always have potential to increase the scope of investigations without necessity to increase consumption of available material resources [10].

Figure 1 illustrates total amount and revenue from research and development per one academic employee.

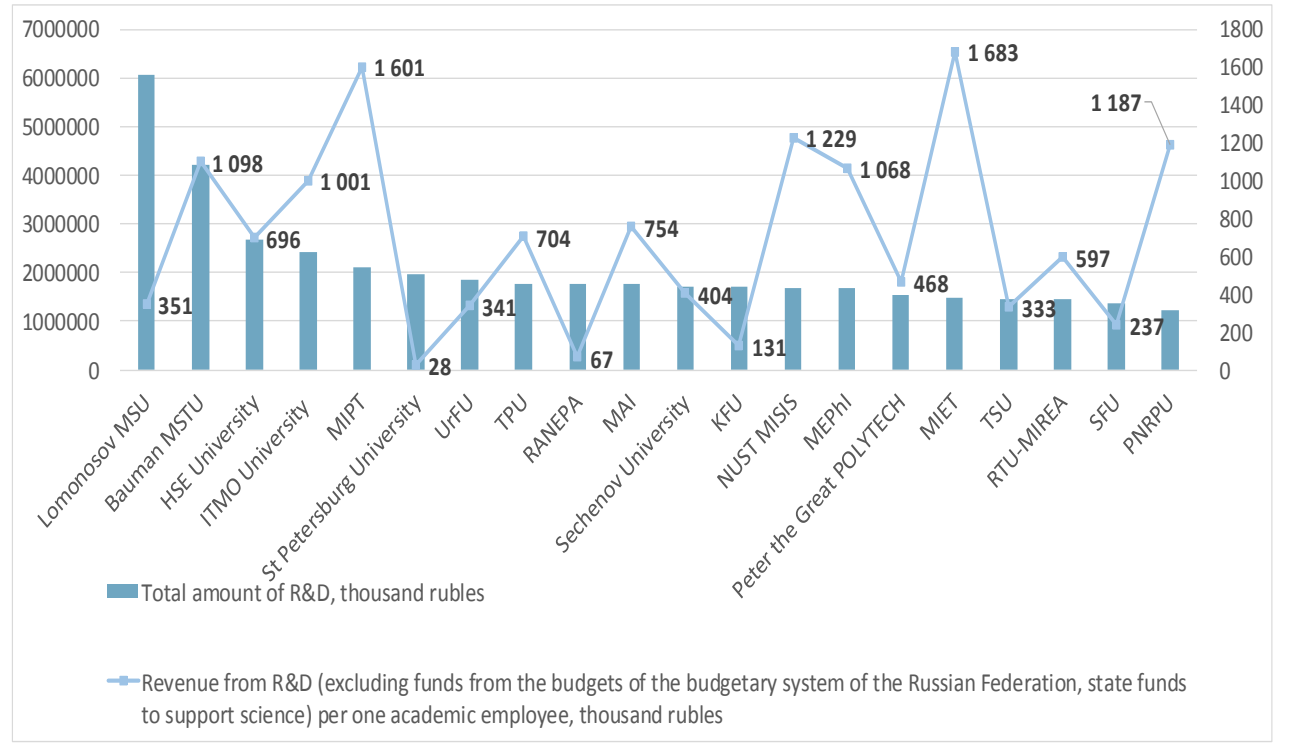

Fig. 1. Total amount and revenue from research and development per one academic employee in Russian Universities in 2018 (Source: compiled by the authors according to the data of the Ministry of Science and Higher Education of the Russian Federation).

Figure 2 illustrates comparisons of total publications of universities in RSCI with their publication in its core, supported by the Hirsch index. 


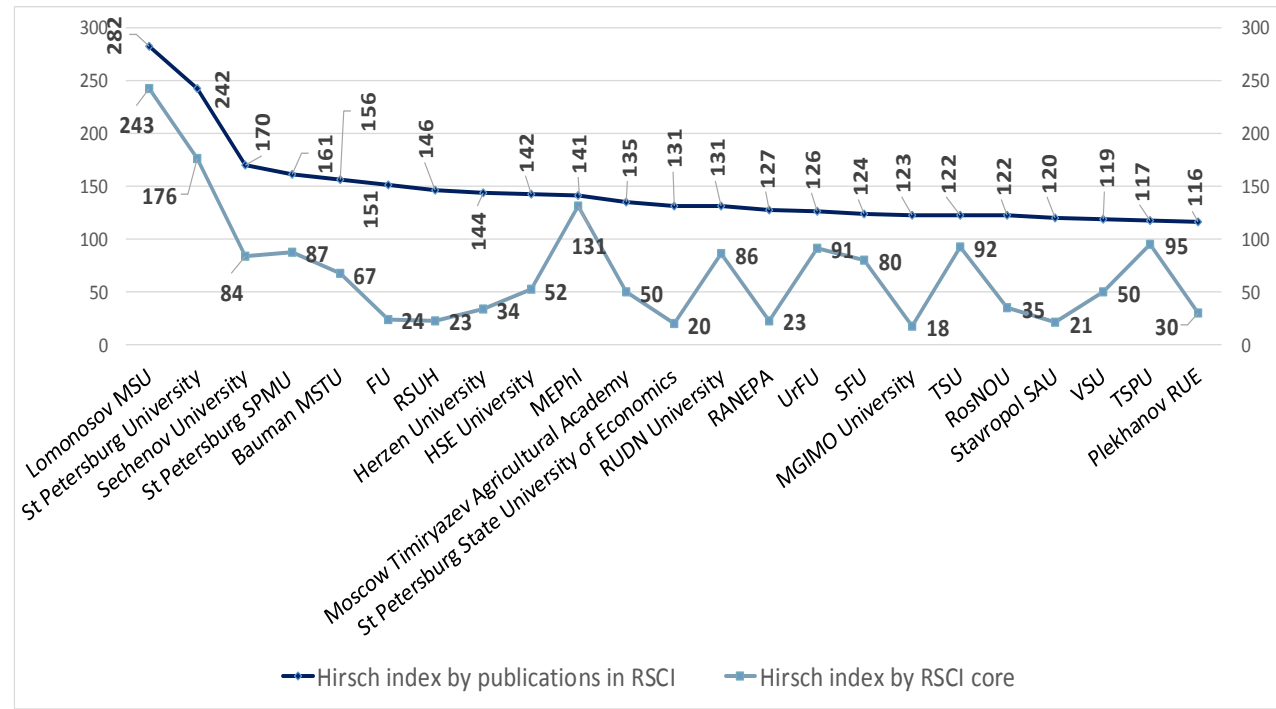

Fig. 2. Hirsch index by all publications in RSCI and in RSCI Core by cumulative totals in Russian Universities in 2018 (Source: compiled by the authors according to RSCI).

Figure 3 illustrates the number of scientific publications of researchers affiliated with leading Russian universities performed in collaboration with researchers from other entities in 2014-2018.

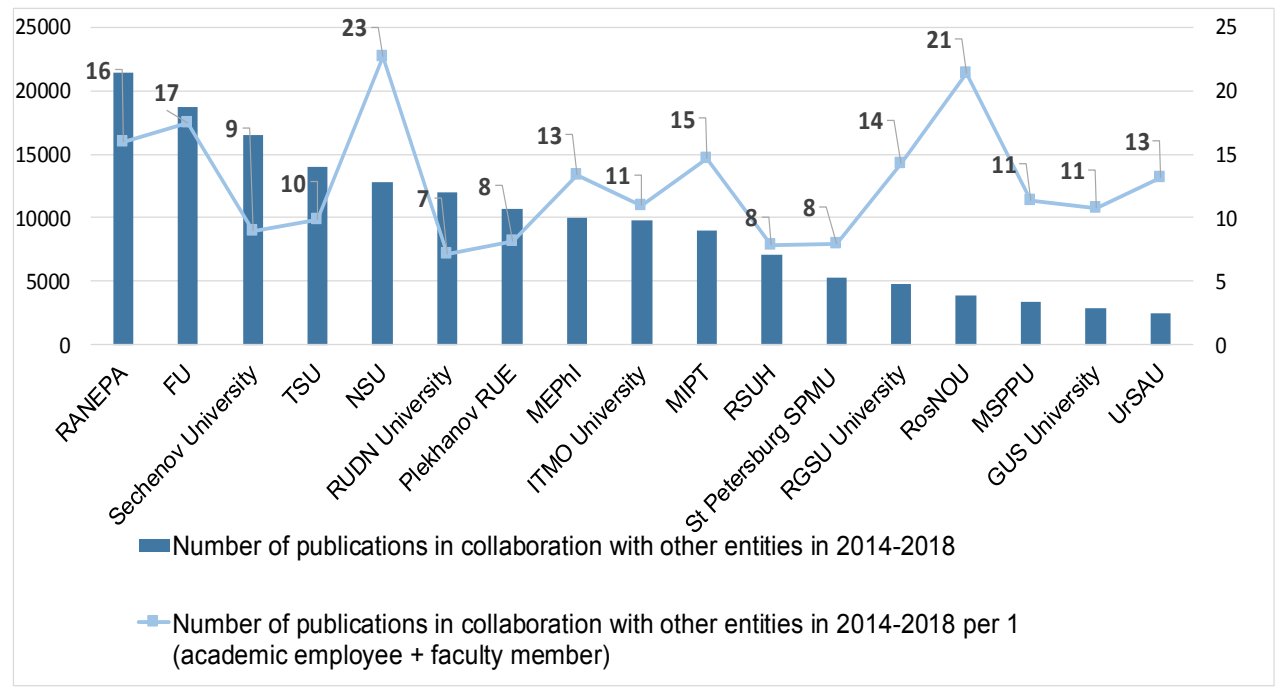

Fig. 3. Number of scientific publications by university affiliated researchers in collaboration with researchers of other entities in 2014-2018. Leaders. (Compiled by the authors according to RSCI).

Figure 4 illustrates the indicators of universities in their media activity. 


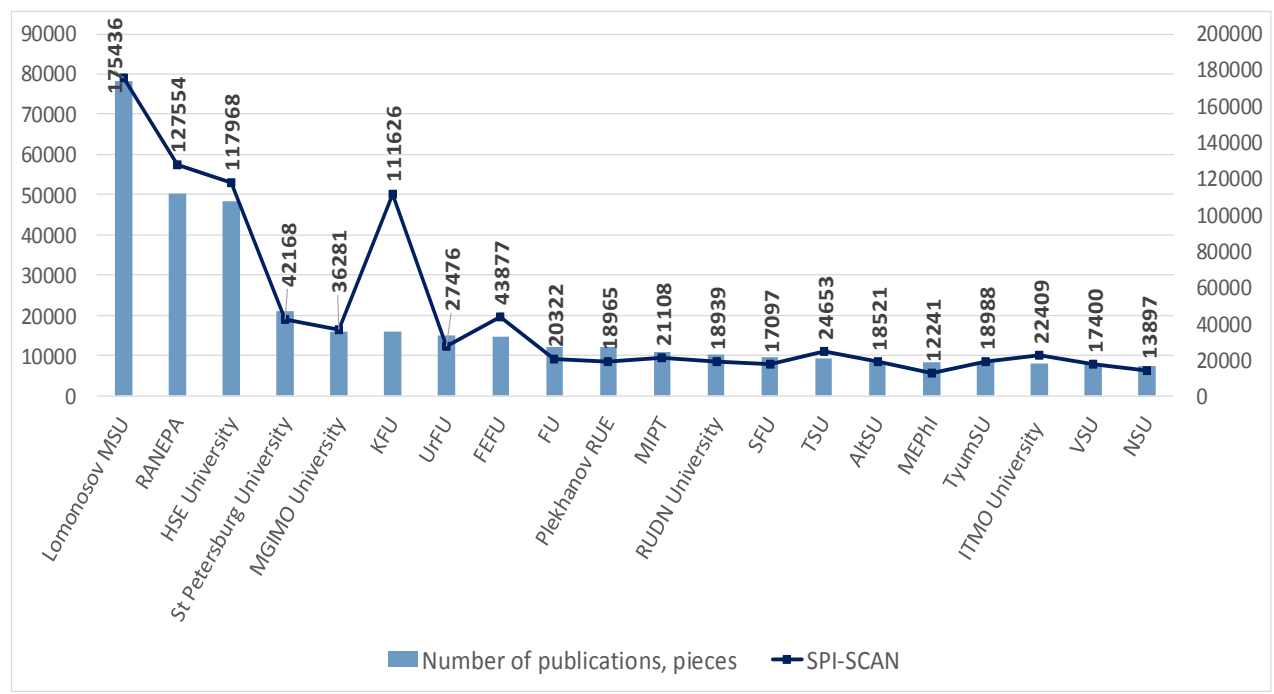

Fig. 4. Publication activity of the universities in 2018 (Compiled by the authors according to SCANInterfax).

\section{Conclusion}

On the basis of the obtained experimental results, taking into account the existing approaches and applied methods, the following main trends of development of modern universities are proposed regarding provision of competitiveness and solution to various problems and performed functions, in particular, training well-qualified and requested specialists for national economy $[11,12]$.

It is believed that transition to orientation of students to creative approach to studying will be a trend in the future. This assumes transition from final qualification examinations to protection of fully functional project, performed generally on interdisciplinary basis and in collaboration with students of various departments or even universities, including presentation of startups $[13,14]$.

A teacher now is not a mentor but a senior partner in studies, cognition, who allows disputes and disagreement with proposed for discussion dogmas.

In the future, we will face development and domination of another trend in development of universities: education technologies (EdTech).

In the short term, the design of teaching and education will be by far more accessible, efficient, and individualized.

The system of higher education in Russia is in the course of reforming and transformation. Modern university is a dynamically developed structure being included into the international network of studies, education, culture, socialization, development of entrepreneurship, combining the work of scientists, experts, analytics, governmental officers and other participants for dialogue and solution to the problems for development of the country and regions [15].

\section{References}

1. P. Shchedrovitsky, Obrazovatelnaya Politika [Educational Policy], 1(51), 11-16 (2011) 
2. M. Brusoni, R. Damian, J.G. Sauri, S. Jackson, H. Kömürcügil, M. Malmedy, O. Matveeva, et al., The concept of excellence in higher education. ENQA Occasional Paper (Brussels, 2014)

3. G.S. Drori, G. Delmestri, A. Oberg, Higher Education, 71(2), 163-180 (2016). https://doi.org/10.1007/s10734-015-9894-6

4. J. Salmi, The challenge of establishing world-class universities (The World Bank, Washington, 2009)

5. P.G. Altbach, Studies in Higher Education, 38(3), 316-330 (2013). https://doi.org/10.1080/03075079.2013.773222

6. E.V. Balatsky, V.V. Sergeeva, Voprosy Ekonomiki [Economics Questions], 2, 133148 (2014). https://doi.org/10.32609/0042-8736-2014-2-133-148

7. I. V. Arzhanova, M. V. Shiryaev, S. N. Mityakov, Vysshee Obrazovanie v Rossii [Higher education in Russia], 28(12), 23-35 (2019). https://doi.org/10.31992/08693617-2019-28-12-23-35

8. J. Brankovic, L. Ringel, T. Werron, Zeitschrift fur Soziologie [Journal of Sociology], 47(4), 270-288 (2018)

9. F.L. Collins, G.-S. Park, Higher Education, 72(1), 115-129 (2016). https://doi.org/10.1007/s10734-015-9941-3

10. J.M. Pastor, L. Serrano, Scientometrics, 109(2), 1255-1281 (2016). https://doi.org/10.1007/s11192-016-2102-3 10.

11. D. A. Endovitsky, V. V. Korotkikh, M. V. Voronova, Vysshee Obrazovanie v Rossii [Higher Education in Russia], 29(2), 9-26 (2020). https://doi.org/10.31992/0869-36172020-29-2-9-26

12. P. A. Zhdanov, N. A. Polikhina, E. Yu. Sema, L. V. Kazimirchik, I. B. Trostyanskaya, A.A. Barsukov, Vysshee Obrazovanie v Rossii [Higher education in Russia], 28(11), 155-167 (2019). https://doi.org/10.31992/0869-3617-2019-28-11-155-167

13. D. V. Petrosyants, V. V. Zubenko, P. S. Seleznev, I. V. Arzhanova, Vysshee Obrazovanie v Rossii [Higher Education in Russia], 29(5), 22-33 (2020). https://doi.org/10.31992/0869-3617-2020-29-5-22-33

14. E. Ya. Kogan, N. Yu. Postalyuk, T. G. Kuteinitsyna, Vysshee Obrazovanie v Rossii [Higher Education in Russia], 28(7), 9-18 (2019). https://doi.org/10.31992/0869-36172019-28-7-9-18

15. J.-P. Guironnet, N. Peypoch, Socio-Economic Planning Sciences, 62, 44-55 (2018). https://doi.org/10.1016/j.seps.2017.07.003 